Original article

\title{
Review of COVID-19 epidemiology and public health response in Europe in 2020
}

\author{
Mehak Nanda, Aashima, Rajesh Sharma \\ University School of Management and Entrepreneurship, Delhi Technological University, Vivek Vihar, Phase-2, New Delhi, India
}

\section{A R T I C L E I N F O}

\section{Keywords:}

COVID-19

Europe

Epidemiology

Stringency

Public health response

\begin{abstract}
A B S T R A C T
Objective: This study focuses on the epidemiology of COVID-19 in Europe and investigates public health response in severely hit countries.

Methods: European Centre for Disease Prevention and Control, Oxford COVID-19 Government Response Tracker and Health System Response Monitor were referred. The relationship between stringency index and COVID-19 cases, and between speed of stringency implementation and growth of cases was examined using linear regression.

Results: The case-fatality ratio (CFR) of Europe (2.35\%) was higher than the global CFR (2.2\%). United Kingdom, Russia, France, Italy, Spain, and Germany together, accounted for $61.15 \%$ of cases and $65.62 \%$ of deaths in Europe. Significant relationship was observed between growth of COVID-19 cases and late substantive stringency imposed by countries. Population aged 65 and above $(r=0.9037, p<0.01)$ and male population $(r=0.8701, p$ $<0.01$ ) were significantly and positively correlated with COVID-19 deaths. The public health system of even big European countries encountered roadblocks, such as shortages of healthcare resources and deferral of nonCOVID-19 treatments while dealing with the unprecedented pandemic.

Conclusion: Even big and richest European countries delayed the implementation of non-pharmaceutical interventions which led to rapid virus transmission. The pandemic has posed a reminder to make the public health system more resilient, as epidemics and pandemics of this nature will continue to threaten in future as well.
\end{abstract}

\section{Introduction}

The emergence of Severe Acute Respiratory Syndrome Coronavirus 2 (SARS-CoV-2), commonly known as COVID-19, in Wuhan, China, in December 2019 has led to a severe global public health crisis. On January 30, 2020, the World Health Organization declared COVID-19 as the sixth public health emergency of international concern. ${ }^{1}$ COVID-19 has already impacted 223 countries/territories with more than 108 million cases and 2 million deaths worldwide as of February 14, 2021. ${ }^{2}$

To curb the virus transmission, countries adopted large-scale nonpharmaceutical interventions such as social distancing (e.g. banning mass gatherings and events), closures of schools, businesses, and public spaces, international travel restrictions, and mandatory mask-wearing. Overall, most government interventions have slowed down infection rates to varying degrees. ${ }^{3}$ A global effort has led to the successful development of multiple vaccine candidates for protection against COVID-19. However, multiple new variants of the virus have been reported towards the end of 2020 such as B.1.1.7 in United Kingdom (UK),
B.1.351 in South Africa and P.1 in Brazil that are associated with increased transmissibility. ${ }^{4}$ Mutation of SARS-CoV-2 has led to the imposition of new rounds of lockdown, curfew and suspension of international flights amidst concerns over the new strains and rapidly soaring cases.

Europe presents an interesting case with few of the countries having one of the best public health systems. ${ }^{5}$ Most European countries have achieved universal (or near universal) coverage of healthcare costs for a core set of services, usually including doctor consultations, tests and examinations, and hospital care. ${ }^{6}$ Seven European countries are among the top ten countries ranked by their healthcare systems across the world; France, Italy, San Marino, Andorra, Malta, Spain, and Austria. 5,7 The biggest factors in driving their top rankings are affordability and access. ${ }^{7}$ Despite that Europe continues to be the global epicenter of the virus accounting for $34 \%$ of COVID-19 cases and deaths as of February $14,2021 .^{2}$

In this study, we attempted to describe the COVID-19 burden in European region over a year in a comprehensive manner. First, we

\footnotetext{
* Corresponding author.

E-mail address: rajesh.sharma@dtu.ac.in (R. Sharma).
} 
describe the epidemiology of COVID-19 in terms of cases, deaths, incidence and mortality rate (per 100,000 population), and case-fatality ratio (CFR) from January 2020 to January 2021. Second, we described how the European countries varied in terms of speed and level of stringency imposed. Third, we estimated the relationship between speed of implementing substantial stringency and growth rate of COVID-19 cases. Fourth, we examined the correlation between socio-economic factors such as population aged 65 years and above, male population, population density, and per capita income with number of COVID-19 related cases and deaths. Lastly, we studied and described the public health system response of most severely-hit and richest European nations (UK, Russia, France, Italy, Spain, and Germany).

\section{Data and methodology}

The data pertaining to COVID-19 cases and deaths for 47 European nations/territories (Annexure 1) was extracted from European Centre for Disease Prevention and Control (ECDC). ${ }^{8}$ The Health System Response Monitor ${ }^{9}$ was referred for extracting information about public health response of most severely-hit ${ }^{8}$ and richest ${ }^{10}$ European countries (UK, Russia, France, Italy, Spain, and Germany). Five out of these six countries are also among the top 25 countries with best healthcare systems in the world with France ranked first, followed by Italy (Rank 2), Spain (Rank 7), UK (Rank 18) and Germany (Rank 25). ${ }^{5}$

Stringency index (SI) was taken from Oxford COVID-19 Government Response Tracker (OxCGRT). ${ }^{11}$ The SI is based upon nine non-pharmaceutical interventions such as closure of schools and work places, international and domestic travel restrictions, ban on public gatherings, testing and contact tracing policies. ${ }^{12}$

To estimate the relationship between the speed of stringency imposed by the government and COVID-19 infection rate, we calculated the average weekly log growth rate of COVID-19 cases in each European country during January 2020 to July 2020 . We also considered the time, a country took to reach a score of 40 out of 100 on the SI since it first reported COVID-19 case. A threshold of 40 allows to capture a substantive response by the government. ${ }^{12}$ We estimated the relationship using following simple linear regression equation (1).

$\mathrm{Y}=\beta_{0}+\beta_{1} \mathrm{X}+\mu$

Where in $\mathrm{X}$ is the explanatory variable (weeks to reach SI $>40$ ) and $\mathrm{Y}$ is the dependent variable (average weekly log growth rate of COVID-19 cases), $\mu$ is the random error term.

We estimated the relationship between average monthly cases (dependent variable) and average monthly SI (independent variable), using panel data models which can account for both country-specific and time variation. Following equation was used to estimate the relation:

$\mathrm{Y}_{\mathrm{it}}=\alpha_{\mathrm{i}}+\beta \mathrm{X}_{\mathrm{it}}+\mathrm{u}_{\mathrm{it}}$

In the above equation, $\mathrm{Y}$ denotes average monthly cases and $\mathrm{X}$ denotes average monthly SI. Here $i=1,2,3, \ldots$ indexes country; $t=1,2,3$, ...indexes time; $\alpha_{\mathrm{i}}$ are country-specific intercepts that capture heterogeneities across countries.

To analyze the correlation between COVID-19 cases and deaths with different socio-economic variables (such as population aged 65 years and above, male population, population density and GDP per capita), data were retrieved from the World Development Indicators database of World Bank.

\section{Results}

\subsection{Epidemiology of COVID-19 in Europe}

\subsubsection{Epidemiology of cases and deaths}

In Europe, the first case of COVID-19 was recorded in the beginning of January 2020. During January 2020 to July 2020, the highest number of cases were recorded in April $(850,681)$, which came down to 445,880 in July. A further resurgence of cases occurred in August (752,209), with highest number of cases recorded in November $(7,360,373)$ (Supplementary Fig. 1). As of week 5 of 2021, Eastern Europe has been the most severely hit region with 9,856,455 cases and 209,230 deaths, followed by $8,369,494$ cases and 193,963 deaths in Western Europe. The second highest number of deaths were reported in Southern Europe $(197,475)$.

There were six countries in Europe, which accounted for $61.15 \%$ of total COVID-19 cases in Europe: Russia $(3,983,197,12.69 \%)$, UK $(3,959,784,12.61 \%)$, France $(3,337,048,10.63 \%)$, Spain $(2,989,085$, $9.52 \%)$, Italy $(2,636,738,8.4 \%)$, and Germany $(2,288,545,7.29 \%)$. These six countries also accounted for $65.62 \%$ of COVID-19 related deaths in Europe: Russia (77,068, 10.45\%), UK (112,798, 15.29\%), France $(78,965,10.7 \%)$, Spain $(62,295,8.44 \%)$, Italy $(91,273,12.37 \%)$, and Germany $(61,675,8.36 \%)$. Holy See, Monaco, Isle of Man, Iceland and Faroe Islands witnessed least number of cases and deaths and Holy See has not reported any deaths as of week 5 of 2021 (Fig. 1).

\subsubsection{Epidemiology in terms of case-fatality ratio (CFR)}

The overall CFR of the European region was $2.35 \%$, varying from $2.12 \%$ in Eastern Europe to $2.54 \%$ in Northern and Southern Europe. The CFR was also heterogeneous across European countries varying from Faroe Islands $(0.15 \%)$ and Iceland $(0.48 \%)$ to Bulgaria (4.17\%) and Isle of Man (5.76\%).

\subsubsection{Epidemiology in terms of incidence and mortality rate (per 100,000 population)}

In terms of incidence and mortality rate (per 100,000 population) the picture is different. Andorra $(13,288.48 / 100,000)$ reported the highest incidence rate followed by Gibraltar $(12,314.7)$ and Montenegro $(10,386.67)$, and the lowest was reported in Finland (867.09) and Isle of Man (510.58). The number of deaths per 100,000 population (mortality rate) was the highest in San Marino (203.78) followed by Slovenia (187.18), and lowest was reported in Faroe Islands (2.04) followed by Iceland (8.55).

\subsection{Stringency, speed of implementation and COVID-19 cases}

Stringent interventions pertaining to non-pharmaceutical response holds the key in containing virus spread. European countries varied in terms of speed of response and degree of stringency (Table 1). Many European countries started implementing restrictions (SI $>0$ ) even before witnessing the first COVID-19 cases. Countries such as Albania, Bosnia and Herzegovina, Bulgaria, Slovak Republic, Malta, Hungary, Poland, San Marino, and Czech Republic were relatively prompt in implementing substantial stringency (SI $>40$ ) than other European nations (UK, Germany, Russia, Spain, France, Belgium, and Sweden). Countries also differed in maximum stringency imposed and in the time taken to reach maximum stringency. The majority of countries implemented highest level of SI during the month of March and April 2020. In most European countries, the SI began to rise considerably again from November 2020 as new cases resurged.

From January 2020 to July 2020, the average log growth rate of cases was significantly associated with the time (in weeks) it took to reach SI greater than 40 since the first reported case. It was statistically related with a coefficient of 1.9341 , which signifies that with each additional week between the country's first case and reaching SI greater than 40 would result in an average growth rate of cases higher by a factor of 1.9341 (Table 2, Fig. 2). We also regressed average monthly cases over average monthly SI and found that average monthly SI exerts significant (4.196e-07) and positive influence (44.35) on average monthly cases (Table 3 ). Hausman test favoured fixed effects model over random effects model $(\mathrm{p}<0.01)$.

As there may be delayed response of stringency on number of cases, we also estimated the relationship by taking one month lag of the 

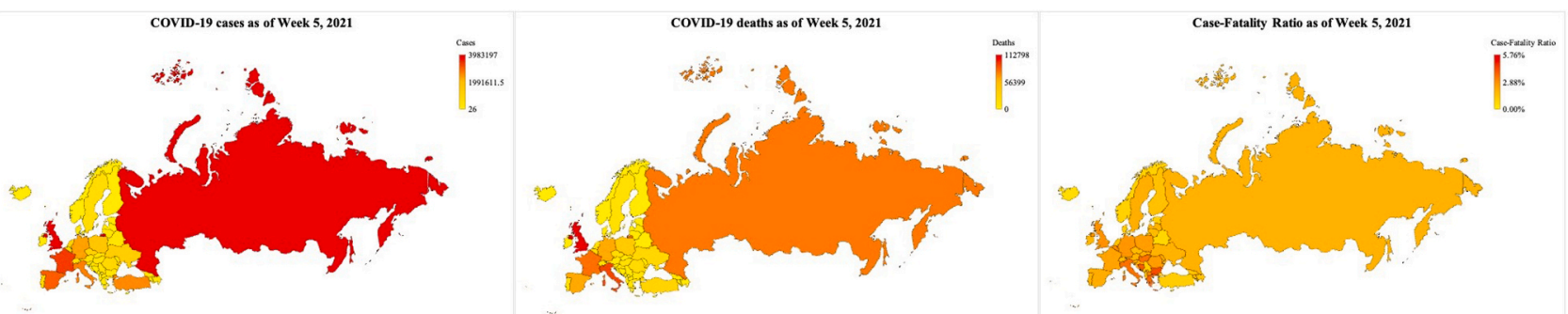

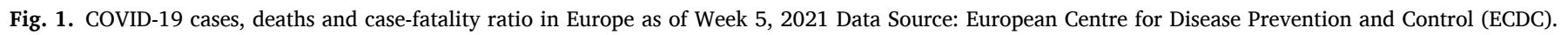

explanatory variable (average monthly cases) to examine the effect of current month's stringency on next month's cases. The relation was found to be significant and positive (Table 3 ).

\subsection{Socio-economic factors and COVID-19 cases and deaths}

Population aged 65 years and above was significantly and positively correlated with COVID-19 cases $(\mathrm{r}=0.9306, \mathrm{p}<0.01)$, and deaths $(\mathrm{r}=$ $0.9037, \mathrm{p}<0.01$ ). Male population was also significantly and positively correlated with COVID-19 cases $(\mathrm{r}=0.9227, \mathrm{p}<0.01)$, and deaths $(\mathrm{r}=$ $0.8701, \mathrm{p}<0.01)$. Population density and GDP per capita were not significantly correlated with either COVID-19 cases or deaths (Table 4).

\subsection{Response of public health system}

COVID-19 forced countries to adopt unprecedented measures. The public health response in most severely hit countries is summarised in Supplementary Table 1. While managing the pandemic, even the richest economies of Europe reported shortages of health resources. Inadequacy of personal protective equipment (PPE), ventilators, facemasks, testing material and capacity was reported in Italy. ICU specialists in Italy were left with no choice but to deny ventilation to the frailest and rationalise the health resources to those who were most likely to benefit and survive. UK went into COVID-19 crisis with a pre-existing shortage of nurses, doctors and allied health professionals in health and social care. A deferral of non-COVID-19 care was also observed. For instance, in the first half of 2020 , Spain witnessed a $36 \%$ decrease in elective surgical interventions compared to 2019, reflecting the consequences of lockdown on hospital activities from March 15 to June 21, 2020. Economies tried to streamline the resources by diverting funds toward building up health resources and infrastructure (such as increasing testing capacity, hospital beds, health professionals, etc). Video and telephone consultations were scaled-up not only for COVID-19 but for other diseases, too. Numerous digital tools such as mobile apps or web platforms were employed for remote health monitoring, consultations and contact tracing. For instance, Italy witnessed the launch of 174 digital initiatives by June 11, 2020, of which, 50 were COVID-specific, whereas others were dedicated to diabetology, cardiology, general medicine, oncology, and psychology. Also, Moscow used its network of facial recognition cameras to enforce quarantine and Murmansk region in Russia used electronic bracelets to monitor self-isolating and suspected COVID-19 patients (Supplementary Table 1).

\section{Discussion}

Europe again witnessed a resurgence of cases towards the end of 2020, and continues to be the second most affected after Americas, accounting for more than one-third of COVID-19 cases and deaths. ${ }^{2}$ The CFR of Europe (2.35\%) was higher than the global CFR (2.2\%) and CFR of South-East Asian region (1.53\%). ${ }^{2}$ During the first wave of COVID-19, majority of European nations were unprepared for the pandemic. Masks were made mandatory in many Asian countries since the beginning of COVID-19 outbreak; however, in the United States and few European countries, health officials discouraged facemasks, partly because supplies were initially low and healthcare workers needed them on priority. ${ }^{13}$ The experience of Asian countries like Japan and South Korea provides direct evidence toward the benefit of facemasks. ${ }^{14}$

Consistent with previous studies, ${ }^{15,16}$ our findings also reveal that COVID-19 deaths are significantly and positively correlated with population aged 65 years and above, and male population. The observed male-biased COVID-19 severity and mortality may be due to several possible factors such as higher expression of angiotensin-converting enzyme-2 (ACE 2; receptors for coronavirus) in males than females, ${ }^{17,18}$ immune suppressive effect of testosterone and immune enhancing effect of estrogen, ${ }^{19}$ lifestyle behaviours (higher levels of smoking and drinking among men), ${ }^{17-19}$ and relatively higher prevalence of underlying comorbidities (e.g. cardiovascular disease, hypertension, and chronic lung disease) among men. ${ }^{17}$ Also, the $\mathrm{X}$ chromosome contains a high density of immune-related genes; therefore, females generally have stronger innate and adaptive immune responses than males. ${ }^{20}$ The number of comorbid conditions steadily increases with age leading to increased mortality in older patients. ${ }^{21}$ However, we observed a very low and insignificant correlation between number of incident cases and population density. A study on COVID-19 cases and death rates of 913 urban counties in the United States also found that the county density is not significantly related to infection rate. $^{22}$

The most severely affected European countries in terms of cases and deaths were also late in implementing substantial restrictions (SI $>40$ ) since first reported case: UK (49 days), Germany (48 days), Russia (44 days), Spain (38 days), France (37 days), and Italy (23 days). We found a significant relationship between the growth of COVID-19 cases and late substantive stringency (SI $>40$ ) imposed by the countries. Studies agreed that a combination of non-pharmaceutical interventions showed a substantial and rapid effect on the spread of COVID-19. ${ }^{23}$ A study noted that Italy delayed imposing restrictive measures, and a nationwide lockdown was implemented only in March 2020. ${ }^{24}$ Before that only Northern Italy was under lockdown and not the central and southern Italy, which led to movement of cases to South and eventually to the entire country. ${ }^{24}$ Another study reported that Italy, Spain and UK failed to estimate the fatal impact of the pandemic and delayed containment measures. ${ }^{25}$ No desire for banning mass gathering until second week of March 2020 in UK was observed. ${ }^{26}$ Also, carnival celebration in Germany, soccer games in Italy, and packed concert stadiums in Britain led to swift virus spread in early $2020 .^{27}$ Russia also underestimated the epidemic for a long time and then undertook incoherent and half-hearted measures such as stopped importation of virus from China; but risks associated with importation of cases from Europe were underestimated. $^{28}$

On the contrary, Eastern European countries swiftly reached SI $>40$; Czech Republic (9 days), Bulgaria (5 days), Poland (8 days), and Slovak Republic (5 days) that helped in containing the virus transmission initially. Czech Republic and Slovak Republic introduced lockdowns before they had recorded any deaths ${ }^{29}$ and made it mandatory for people to wear masks outside the home since beginning. ${ }^{28}$ Slovak Republic achieved early and effective quarantine measures and Slovak 
Table 1

Stringency across Europe.

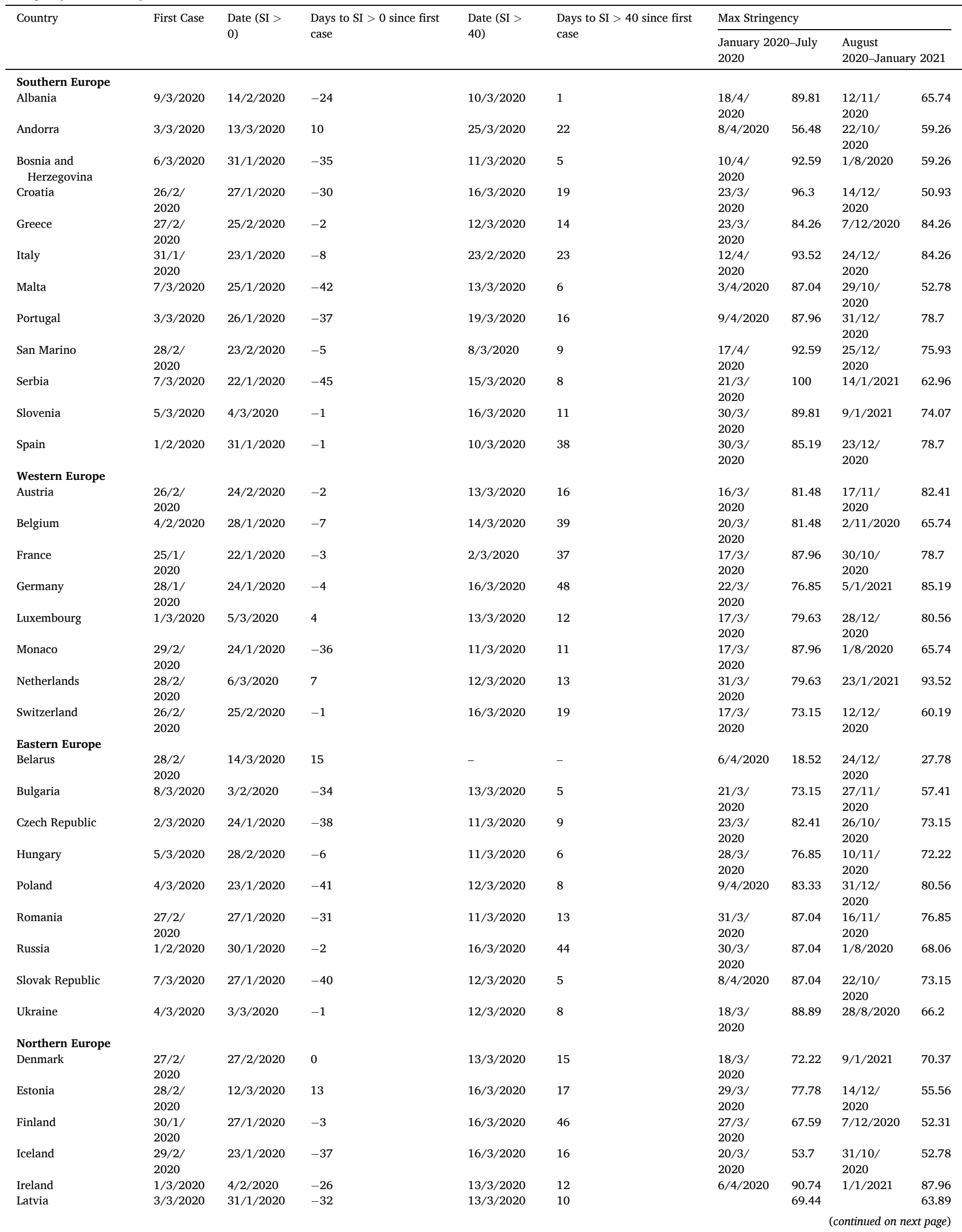


Table 1 (continued)

\begin{tabular}{|c|c|c|c|c|c|c|c|c|c|}
\hline \multirow[t]{2}{*}{ Country } & \multirow[t]{2}{*}{ First Case } & \multirow{2}{*}{$\begin{array}{l}\text { Date }(\mathrm{SI}> \\
0)\end{array}$} & \multirow{2}{*}{$\begin{array}{l}\text { Days to SI }>0 \text { since first } \\
\text { case }\end{array}$} & \multirow{2}{*}{$\begin{array}{l}\text { Date (SI > } \\
40)\end{array}$} & \multirow{2}{*}{$\begin{array}{l}\text { Days to SI }>40 \text { since first } \\
\text { case }\end{array}$} & \multicolumn{4}{|c|}{ Max Stringency } \\
\hline & & & & & & $\begin{array}{l}\text { January } 20 \\
2020\end{array}$ & 0-July & $\begin{array}{l}\text { August } \\
\text { 2020-Janua }\end{array}$ & 2021 \\
\hline & & & & & & $\begin{array}{l}27 / 3 / \\
2020\end{array}$ & & $\begin{array}{l}30 / 12 / \\
2020\end{array}$ & \\
\hline Lithuania & $\begin{array}{l}28 / 2 / \\
2020\end{array}$ & $26 / 2 / 2020$ & -2 & $16 / 3 / 2020$ & 17 & $\begin{array}{l}16 / 3 / \\
2020\end{array}$ & 81.48 & $\begin{array}{l}21 / 12 / \\
2020\end{array}$ & 76.85 \\
\hline Norway & $\begin{array}{l}27 / 2 / \\
2020\end{array}$ & $31 / 1 / 2020$ & -27 & $12 / 3 / 2020$ & 14 & $\begin{array}{l}24 / 3 / \\
2020\end{array}$ & 79.63 & $23 / 1 / 2021$ & 70.37 \\
\hline Sweden & $5 / 2 / 2020$ & $9 / 3 / 2020$ & 33 & $19 / 3 / 2020$ & 43 & $4 / 4 / 2020$ & 64.81 & $\begin{array}{l}14 / 12 / \\
2020\end{array}$ & 69.44 \\
\hline United Kingdom & $1 / 2 / 2020$ & $20 / 1 / 2020$ & -12 & $21 / 3 / 2020$ & 49 & $\begin{array}{l}24 / 3 / \\
2020\end{array}$ & 79.63 & $5 / 1 / 2021$ & 81.48 \\
\hline
\end{tabular}

Table 2

Relationship between growth rate in COVID-19 cases and time (in weeks) to reach SI $>40$.

\begin{tabular}{ll}
\hline & Log growth rate in COVID-19 cases as dependent variable \\
\hline Time to reach SI $>40$ & $1.9341^{* *}$ (SE: 0.091$)$ \\
Intercept & $31.772^{* * *}$ (SE: 2.124$)$ \\
$\mathrm{R}^{2}$ & 0.2069 \\
$\mathrm{~N}$ & 36 \\
\hline
\end{tabular}

$* / * * / * * *$ denote statistical significance at $10 / 5 / 1 \%$, respectively.

citizens behaved more responsibly. ${ }^{28}$ A study comparing public policy response in Czech Republic, Russia and Slovak Republic, reported that Slovak Republic was the best performer, Czech Republic was good performer and Russia was reported as a limited performer. ${ }^{28}$ Similarly, the Nordic region was lauded for its early success in combating the virus spread through prompt response, strong information and surveillance system, aggressive testing and contact tracing. ${ }^{30}$

Delays in identifying initial warning signs left many governments blinded to the unprecedented scale of the pandemic. Countries varied in terms of response and time to respond and the possible reason could be that at first, countries did not have a standard benchmark about the interventions to be implemented i.e., when to impose lockdown, the rules of quarantine and social distancing. Paradoxically, European countries with few of them having one of the best healthcare systems
Table 3

Relationship between average monthly cases and average monthly stringency index (SI).

\begin{tabular}{|c|c|c|}
\hline & I & II \\
\hline & $\begin{array}{l}\text { Average monthly cases as } \\
\text { dependent variable }\end{array}$ & $\begin{array}{l}\text { Average monthly cases with one } \\
\text { month lag as dependent variable }\end{array}$ \\
\hline $\begin{array}{l}\text { Average } \\
\text { monthly SI }\end{array}$ & $44.3553^{* * *}$ (SE: 8.614) & $22.5383 * *$ (SE: 8.2336) \\
\hline $\mathrm{R}^{2}$ & 0.053402 & 0.0172 \\
\hline $\mathrm{N}$ & 39 & 39 \\
\hline Fixed effects & Yes & Yes \\
\hline $\begin{array}{c}\text { Hausman test } \\
\text { p value }\end{array}$ & 0.008204 & $5.311 \mathrm{e}-05$ \\
\hline
\end{tabular}

$* / * * / * * *$ denote statistical significance at $10 / 5 / 1 \%$, respectively.

Table 4

Relation between Socio-Economic variables and COVID-19 cases and deaths.

\begin{tabular}{lll}
\hline Socio-economic variables & $\begin{array}{l}\text { COVID-19 } \\
\text { Cases }\end{array}$ & $\begin{array}{l}\text { COVID-19 } \\
\text { Deaths }\end{array}$ \\
\hline $\begin{array}{l}\text { Population aged 65 years and above }(\mathrm{N}= \\
\text { 39) }\end{array}$ & $0.9306^{* * *}$ & $0.9037^{* * *}$ \\
Male population $(\mathrm{N}=39)$ & $0.9227^{* * *}$ & $0.8701^{* * *}$ \\
Population density $(\mathrm{N}=46)$ & -0.1123 & -0.1021 \\
GDP per capita $(\mathrm{N}=43)$ & -0.1189 & -0.1008 \\
\hline
\end{tabular}

$* / * * / * * *$ denote statistical significance at $10 / 5 / 1 \%$, respectively.

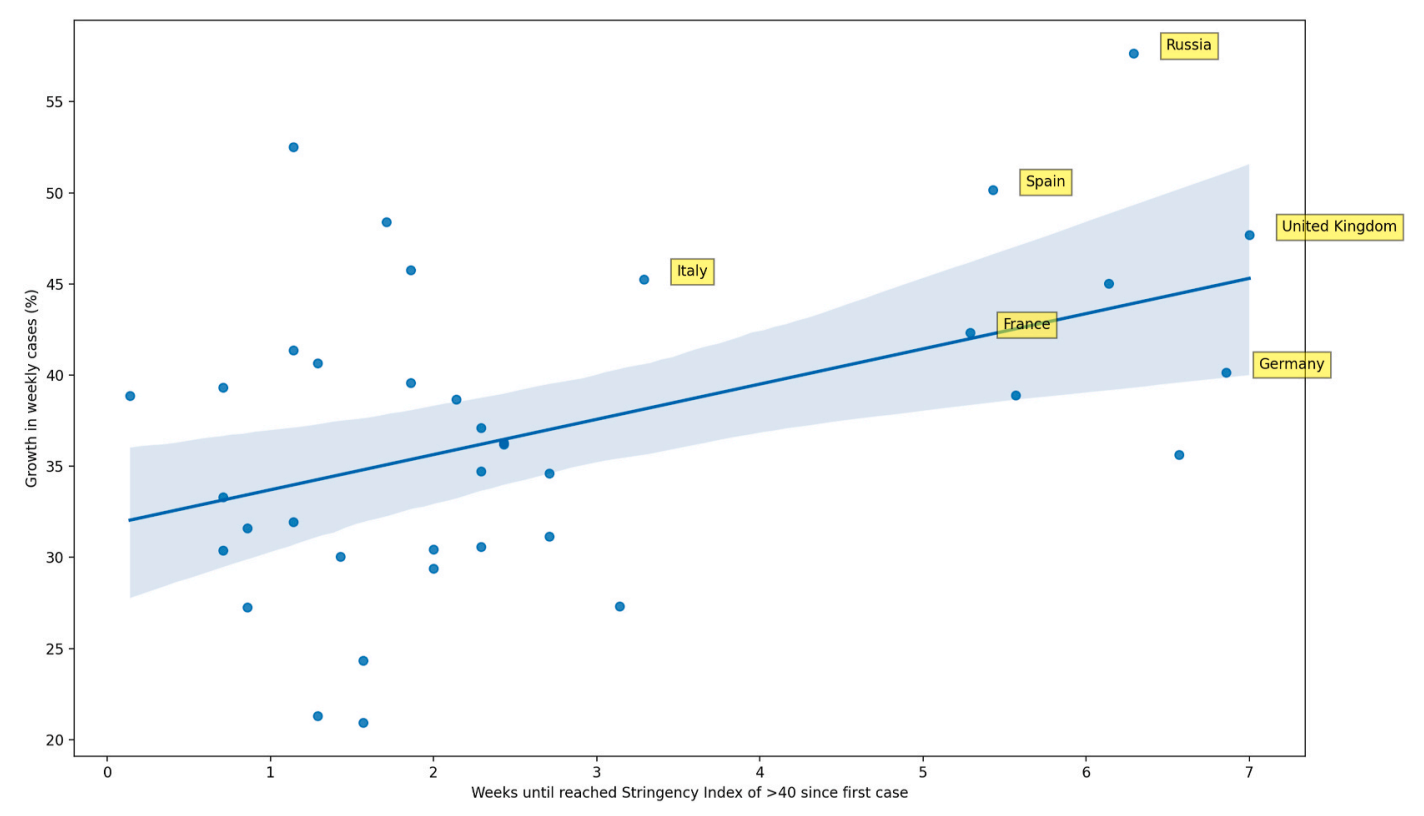

Fig. 2. Speed of government response and growth in COVID-19 cases Data Source: European Centre for Disease Prevention and Control (ECDC) and Oxford COVID19 Government Response Tracker (OxCGRT). 
encountered major roadblocks in terms of insufficient health resources (such as PPE, health personnel, ventilators, masks, etc), and deferrals of non-COVID-19 care. In mid-April, France was testing 5.1 people per 1000 people in comparison to 17 in Germany and 15 in Organization for Economic Co-operation and Development (OECD) countries due to underutilization of public laboratories and lack of necessary material and equipment, and denounced the lack of protection to health workers. ${ }^{14}$ In UK, medical staff reported huge shortage of PPE kits which forced them to triage potential COVID-19 patients with paper facemasks and plastic aprons than visors, gowns, and appropriate masks. ${ }^{26}$ In Italy, hospitals were overcrowded and doctors were left with no choice but to lay their patients on floor mattresses. $^{9}$

A third wave along with sluggish vaccination campaigns and spread of new variants has urged a situation to reinforce strict public health interventions in Europe. ${ }^{31}$ Several European countries started to introduce new lockdown measures in 2021: most regions in Italy returned to lockdown over a three-day Easter weekend ${ }^{32}$; Germany extended its shut down until March 28, 2021. ${ }^{33}$ Much of Europe has lagged behind the United States and UK in deployment of COVID-19 vaccine. ${ }^{33}$ According to Bloomberg's Coronavirus Vaccine Tracker, the European Union had administered eight first doses per 100 people, compared with 33 for UK and 25 for the United States as of first week of March 2021. ${ }^{32}$ In short, supply shortages, vaccine skepticism, bureaucracy and logistical obstacles, have slowed the pace of inoculations in Europe, ${ }^{34}$ which are most prominent issues required to be addressed.

\section{Conclusion}

The big and richest European countries delayed the implementation of non-pharmaceutical interventions which led to rapid virus transmission and exponential rise in the number of cases. Also European countries witnessed shortage of health resources and deferral of nonCOVID care. Europe experienced a catastrophic COVID-19 situation with high death rate, slow vaccine rollouts and spread of new virus strains. According to an ECDC report, ${ }^{35}$ to effectively contain the pandemic, deployment of effective and safe vaccines is needed along with the continuation of non-pharmaceutical interventions. A greater willingness and responsibility to adopt infection prevention practices is required to adapt life in "the new normal". Also, the pandemic has posed a reminder to invest in health infrastructure, upscale utilization of telemedicine $^{36}$ and make the public health system more resilient, as epidemics and pandemics of this nature will continue to threaten in future as well.

\section{Funding}

This research receives no specific grant from any funding agency in the public, commercial or not-for-profit sectors.

\section{Declaration of competing interest}

No conflict of interest has been declared by the author(s).

\section{Appendix A. Supplementary data}

Supplementary data to this article can be found online at https://doi. org/10.1016/j.cegh.2021.100882.

\section{References}

1 Lai CC, Shih TP, Ko WC, et al. Severe acute respiratory syndrome coronavirus 2 (SARS-CoV-2) and coronavirus disease-2019 (COVID-19): the epidemic and the challenges. Int J Antimicrob Agents. 2020;55(3):105924.

2 World Health Organization (WHO). Weekly epidemiological update - 16 February 2021. https://www.who.int/publications/m/item/weekly-epidemiological-update -16-february-2021; 2021. Accessed February 17, 2021.
3 Cross M, Ng SK, Scuffham P. Trading health for wealth: the effect of COVID-19 response stringency. Int J Environ Res Publ Health. 2020;17(23):8725.

4 European Centre for Disease Prevention and Control (ECDC). Infographic: Mutation of SARS-CoV2 - current variants of concern. https://www.ecdc.europa.eu/en/publ ications-data/covid-19-infographic-mutations-current-variants-concern; 2021. Accessed February 5, 2021.

5 World Population Review. Best healthcare in the world 2021. https://worldpopulatio nreview.com/country-rankings/best-healthcare-in-the-world; 2021. Accessed September 8, 2021

6 Oecd Publishing. Health at a Glance: Europe 2018: State of Health in the EU Cycle. Organisation for Economic Co-operation and Development OECD; 2018.

7 International Insurance. Ranking the top healthcare systems by country. https ://www.internationalinsurance.com/health/systems/; 2021. Accessed September 8, 2021.

8 European Centre for Disease Prevention and Control (ECDC). Situation updates on COVID-19. https://www.ecdc.europa.eu/en/covid-19/situation-updates; 2021. Accessed February 10, 2021.

9 World Health Organization (WHO). COVID-19 health system response monitor. https://www.covid19healthsystem.org/mainpage.aspx; 2021. Accessed February 28, 2021.

10 World Population Review. Richest European countries 2021. https://worldpopulat ionreview.com/country-rankings/richest-european-countries; 2021. Accessed September 9, 2021.

11 Coronavirus Government Response Tracker. https://www.bsg.ox.ac.uk/research/ research-projects/coronavirus-government-response-tracker; 2021. Accessed February 9, 2021.

12 Hale T, Hale AJ, Kira B, et al. Global assessment of the relationship between government response measures and COVID-19 deaths. medRxiv. 2020. https://doi. org/10.1101/2020.07.04.20145334.

13 Lewis D. Is the coronavirus airborne? Experts can't agree. Nature. 2020;580(7802): 175.

14 Hassenteufel P. Handling the COVID-19 crisis in France: paradoxes of a centralized state-led health system. Eur Pol Analyst. 2020;6(2):170-179.

15 Pérez-López FR, Tajada M, Savirón-Cornudella R, et al. Coronavirus disease 2019 and gender-related mortality in European countries: a meta-analysis. Maturitas. 2020; 141:59-62.

16 Caramelo F, Ferreira N, Oliveiros B. Estimation of risk factors for COVID-19 mortality-preliminary results. MedRxiv. 2020. https://doi.org/10.1101/ 2020.02.24.20027268.

17 GlobalHealth5050. Men, sex, gender and COVID-19. https://globalhealth5050.org /the-sex-gender-and-covid-19-project/men-sex-gender-and-covid-19/; 2021. Accessed January 21, 2021.

18 Bwire GM. Coronavirus: why men are more vulnerable to Covid-19 than women? SN Comprehen Clinical Med. 2020;2(7):874-876.

19 Agrawal H, Das N, Nathani S, et al. An assessment on impact of COVID-19 infection in a gender specific manner. Stem Cell Rev Rep. 2021;17(1):94-112.

20 Sharma G, Volgman AS, Michos ED. Sex differences in mortality from COVID-19 pandemic: are men vulnerable and women protected? Case Rep. 2020;2(9): 1407-1410.

21 Yanez ND, Weiss NS, Romand JA, Treggiari MM. COVID-19 mortality risk for older men and women. BMC Publ Health. 2020;20(1):1-7.

22 Hamidi S, Sabouri S, Ewing R. Does density aggravate the COVID-19 pandemic? Early findings and lessons for planners. J Am Plann Assoc. 2020;86(4):495-509.

23 Lai S, Ruktanonchai NW, Zhou L, et al. Effect of non-pharmaceutical interventions to contain COVID-19 in China. Nature. 2020;585(7825):410-413.

24 Pisano GP, Sadun R, Zanini M. Lessons from Italy's response to coronavirus. Harv Bus Rev. 2020:27.

25 Khanna RC, Cicinelli MV, Gilbert SS, et al. COVID-19 pandemic: lessons learned and future directions. Indian J Ophthalmol. 2020;68(5):703.

26 Hunter DJ. Covid-19 and the stiff upper lip-the pandemic response in the United Kingdom. N Engl J Med. 2020;382(16):e31.

27 The Wall Street Journal (WSJ). Poorer nations in europe's east could teach the west a lesson on coronavirus. https://www.wsj.com/articles/poorer-eastern-european-nat ions-could-teach-the-west-a-lesson-on-coronavirus-11586718779; 2021. Accessed February 8, 2021.

28 Chubarova T, Maly I, Nemec J. Public policy responses to the spread of COVID-19 as a potential factor determining health results: a comparative study of the Czech Republic, the Russian Federation, and the Slovak Republic. Cent Eur J Public Policy. 2020;14(2):60-70.

29 Paul R. Europe's essential workers: migration and pandemic politics in Central and Eastern Europe during COVID-19. Eur Pol Analyst. 2020;6(2):238-263.

30 Nanda M, Aashima, Sharma R. COVID-19: a comprehensive review of epidemiology and public health system response in nordic region. Int J Health Serv. 2021, 0020731421994840.

31 The Guardian. Third COVID was sweeps across EU and forces new restrictions. https ://www.theguardian.com/world/2021/mar/14/third-covid-wave-sweeps-across-e u-and-forces-new-restrictions; 2021. Accessed March 18, 2021.

32 Aljazeera. Why are COVID cases rising in Europe despite vaccination efforts?. http s://www.aljazeera.com/news/2021/3/16/why-are-covid-cases-rising-in-europedespite-vaccination-efforts; 2021. Accessed March 18, 2021.

33 Business Insider. Photos show what Europe's third COVID-19 wave looks like as hospitalizations mount and Italy enters another lockdown. https://www.businessinsi der.in/science/health/news/photos-show-what-europeaposs-third-covid-19-wavelooks-like-as-hospitalizations-mount-and-italy-enters-another-lockdown/slidelist /81560125.cms; 2021. Accessed March 18, 2021. 
34 The New York Times. Italy imposes lockdown measures as cases spike across Europe https://www.nytimes.com/2021/03/15/world/italy-covid-lockdown.html; 2021. Accessed March 18, 2021.

35 ECDC. Risk Assessment: risk related to the spread of new SARS-CoV-2 variants of concern in the EU/EEA - first update. https://www.ecdc.europa.eu/en/publications- data/covid-19-risk-assessment-spread-new-variants-concern-eueea-first-update;

2021. Accessed February 18, 2021.

36 Aashima Nanda M, Sharma R. A review of patient satisfaction and experience with telemedicine: a Virtual solution during and beyond COVID-19 pandemic. Telemed eHealth. 2021. https://doi.org/10.1089/tmj.2020.0570. 